\title{
Artigo
}

\section{Traduciendo prácticas, tejiendo redes, cruzando fronteras. Itinerarios del feminismo argentino de los '70s*}

Karina Felitti**

\begin{abstract}
Resumen
Este artículo estudia la recepción de las ideas y prácticas del feminismo estadounidense y francés de la segunda ola en la Argentina, sus traducciones y apropiaciones; y la presencia de noticias, informes y entrevistas sobre las organizaciones feministas argentinas y la situación de las mujeres y de los homosexuales bajo la dictadura militar, en las principales revistas feministas francesas de los 70s. La propuesta es reflexionar sobre las circulaciones de saberes, conocimientos y prácticas de los feminismos, la formación de redes transnacionales y de proyectos locales, y la incorporación del discurso de derechos humanos y del enfoque de género a la lucha política.
\end{abstract}

Palabras clave: Feminismos, Argentina, Derechos Humanos, Circulaciones, 1970.

* Recebido para publicação em 13 de janeiro de 2014, aceito em 3 de fevereiro de 2015.

** Docente universitaria em UBA y CIEE/FLACSO - Argentina. Investigadora de CONICET en el Instituto Interdisciplinario de Estudios de Género (IIEGE) de la Facultad de Filosofía y Letras (UBA), Buenos Aires, Argentina. karinafelitti@hotmail.com 
230 Traduciendo prácticas, tejiendo redes, cruzando fronteras

Translating Practices, Building Networks, Crossing Borders. Itineraries of Argentinean Feminisms during The 70s

\begin{abstract}
This article studies the reception of Second Wave American and French feminism in Argentina, their translation and appropriation process; and the reports, news and interviews about Argentinean feminist organizations and women and homosexuals situation under the military dictatorship, published in French feminist journals during the 70s. I propose to reflect on the circulation of knowledge, skills and practices among feminisms, the creation of transnational networks and local projects, and the introduction of Human Rights discourse and gender perspective into political struggles.
\end{abstract}

Key Words: Feminisms, Argentina, Human Rights, Circulation, 1970. 


\section{Introducción}

En la academia feminista latinoamericana la interseccionalidad se ha vuelto imperiosa: el género se combina con la clase, la raza/etnicidad, la edad, la sexualidad, las religiones y las creencias, para visibilizar experiencias particulares, identidades que cuestionan la existencia de un solo tipo de mujer y con ello, de un solo modo de ser y estar feminista. Se habla de "mujeres de color", de "subalternas" y se resiste la categoría "mujeres del tercer mundo", aclarando que no se trata de un grupo homogéneo con intereses y deseos idénticos, y mucho menos víctimas universales a la espera de ser "salvadas" por un feminismo etnocéntrico y colonizador (Vázquez Laba et alli, 2012). Varios trabajos reflexionan sobre la circulación de saberes, conocimientos y prácticas entre Norte y Sur, y las barreras económicas y discursivas que han obstaculizado que las teorías feministas y los conceptos viajen en la dirección opuesta (Bidaseca, 2010; Quijano, 2000), aunque también se reconoce la existencia de un "tráfico de teorías" que permite la reapropiación, quiebra los modelos originales y logra aculturar al centro (De Lima Costa, 2002).

Una de las preguntas clave de estos debates es: ¿quiénes dictan los contenidos de la emancipación y en base a qué criterios? Las polémicas sobre el uso del velo y de las posibilidades emancipatorias de las religiones y las creencias son ejemplos de las tensiones que conllevan estos interrogantes. En los años 60s se puso en crisis la categoría "mujer" a partir de las denuncias y aportes de las feministas afrodescendientes, lesbianas y chicanas. En ese entonces, la experiencia personal adquirió valor $y$ proyección política, mientras se priorizaban demandas de autonomía y libertad en relación al cuerpo y la sexualidad. Estas ideas de la "segunda ola" han sido rescatadas y exacerbadas por nuevas generaciones que incorporan los aportes del feminismo postcolonial a los estudios de género (Bidaseca y Vázquez Laba, 2010; Femenias, 2011 y 2007) y por quienes participan de luchas sociales globales, con mayor disposición a las coaliciones 
transnacionales y una notable diversidad en la composición de los movimientos. Si todo esto constituye una "tercera ola" es un tema de debate; quizás, como afirman algunas, sólo se trate de reafirmar una identidad a partir del matricidio (Snyder, 2008).

En la Argentina estas discusiones son de gran actualidad y han adquirido reconocimiento por parte de la academia y del activismo. Las posibilidades que abrieron las nuevas tecnologías de comunicación ponen al feminismo local a un click de lo que sucede en otros escenarios. La circulación de publicaciones y noticias es basta y se generan propuestas de resistencia globales (Álvarez, 2000) aunque esto tampoco resulta totalmente novedoso. Con menos tecnología pero mucha voluntad, en los años 60s y 70s el tráfico de ideas y prácticas feministas entre los Estados Unidos, Europa y Argentina fue fundamental para la reemergencia $y$ reconfiguración del feminismo argentino.

En el marco de una renovación historiográfica que estudia el pasado reciente desde un enfoque de género, varios trabajos han analizado la emergencia de la "segunda ola" feminista en la Argentina (Rodríguez Agüero y Ciriza, 2012; Trebisacce y Terelli, 2011; Trebisacce, 2010; Felitti, 2010a; Gil Lozano, 2006; Vasallo, 2005; Belucci, 1999; Chejter, 1996; Nari, 2000 y 1996, entre otros). Estos estudios, junto con las memorias de las propias protagonistas (Cano, 1982; Calvera, 1990; Oddone, 2001; Aldaburu, Cano, Rais y Reynoso, 1982), confirman la importancia que tuvieron ciertas lecturas y prácticas del feminismo estadounidense, francés $e$ italiano en las primeras organizaciones y los esfuerzos de "traducción" que esto supuso.

A su vez, esta época bajo el signo de proyectos revolucionarios que terminaron despedazados por el terrorismo de estado, fue un tiempo de exilios. Para muchas militantes esta salida forzosa, impuesta por el miedo y el horror de la represión, resultó una oportunidad para observar otros contextos, mirar a otras mujeres y mirarse a sí mismas. En México, en Brasil o en Francia, las exiliadas tendieron puentes entre ellas y también con las feministas de sus países de acogida, tratando de mantener el 
vínculo con aquellas que habían quedado en sus países de origen (Veiga, 2010).

En este artículo indago en los tráficos de saberes, conocimientos y experiencias del feminismo de la segunda ola, a partir de los itinerarios que trazan las publicaciones de las agrupaciones de la Argentina y de Francia, sus documentos y los recuerdos de sus protagonistas, para reflexionar sobre lo multilocal del feminismo y los procesos de traducción que se pusieron en acción en aquella época (De Lima Costa, 2003). En la primera parte estudio las circulaciones del feminismo estadounidense y francés en la Argentina de los años 60s y 70s. En la segunda, analizo las referencias, informes y entrevistas que hacen las principales publicaciones feministas de Francia y la revista del Frente Homosexual de Acción Revolucionaria (Front homosexuel d'action révolutionnaire) sobre el feminismo argentino y la situación de las mujeres y de los "homosexuales" bajo la última dictadura militar. Estas fuentes aportan importantes datos para la historia del feminismo y del movimiento homosexual en la Argentina, y a su vez, permiten reflexionar sobre los desafíos que supuso la incorporación del discurso de derechos humanos a la lucha política y la "conversión" al feminismo de varias militantes durante sus exilios.

\section{Lecturas, estrategias, agendas}

En la Argentina de los 60s, la mejora en la situación jurídica de las mujeres, las nuevas oportunidades educativas y laborales que se les abrían, y la mayor flexibilidad de las pautas que guiaban la sexualidad y la reproducción, cambiaron la vida de una generación. Quienes mejor vivieron estas transformaciones fueron aquellas jóvenes que se ubicaban en los sectores medios, en un contexto en el que coincidían la modernización de las costumbres, los proyectos revolucionarios, la persistencia de la influencia católica y gobiernos cada vez más autoritarios. Las imágenes de independencia femenina se fueron diseminando en los medios de comunicación y terminaron por consolidar el prototipo de la joven 
"liberada", "rebelde" y "emancipada" de los 70s (Cosse, 2009). Es interesante destacar que estas nuevas posibilidades no fueron resultado directo de luchas feministas. De hecho, el reconocimiento de los derechos políticos femeninos logrado bajo el primer peronismo, con la sanción de la ley de sufragio femenino en 1947, asumió un tono contrario. Este gobierno borró los antecedentes de lucha de las primeras feministas, mientras que las principales referentes de la época se mantuvieron cautas para evitar cualquier gesto de apoyo a un gobierno al que se oponían. La misma Eva Perón había acusado a las feministas de ridículas y resentidas, de estar "dominadas por el despecho de no haber nacido hombres" y de rechazar lo que consideraba la misión natural de la mujer: el hogar y la maternidad (Perón, 1951:265276).

El avance en los derechos políticos femeninos en los ' 50 s se combinó con importantes cambios en el marco jurídico durante la década siguiente, cuando se reconoció la plena capacidad civil de las mujeres, se habilitó el divorcio vincular e incluso, se ampliaron los casos de abortos no punibles a todo embarazo producto de una violación. Sin embargo, estas modificaciones respondieron más a los objetivos modernizadores del gobierno militar de la Revolución Argentina (1966-1970) que a una conciencia estatal sobre los derechos de las mujeres. Lo mismo puede decirse respecto a la extensión de la planificación familiar y la difusión de la píldora anticonceptiva. Ambas eran incentivadas por médicos y trabajadoras sociales que procuraban evitar así algunos de los problemas de las familias numerosas en contextos de marginalidad $y$ de los abortos clandestinos, y no por el Estado que se mostraba preocupado, en cambio, por aumentar los índices de natalidad.

En ese sentido, los años sesentas fueron un momento de preparación y de experimentación de los cambios con sus propias limitaciones. En palabras de Isabella Cosse (2010), se vivió una "revolución discreta", es decir, importantes transformaciones pero también continuidades, marchas y contramarchas, múltiples fisuras que afectaron al orden establecido y no una única revolución. Pese a sus restricciones, las transformaciones fueron notables $e$ 
incluso tuvieron un efecto paradójico sobre las luchas feministas. Hilda Rais, quien militaba en la Unión Feminista Argentina (UFA) a comienzos de los '70s, recuerda:

Cuando una amiga me comentó que estaba en un grupo feminista, a mi me dio un ataque de risa, porque me parecía algo que era del pasado, que no tenía sentido el feminismo en esa época. Que era como ser abolicionista de la esclavitud, algo completamente del pasado (Rais, 2005).

Marcela Nari (2000) halló recuerdos parecidos cuando entrevistó a mujeres que estudiaban en la universidad o que participaban en agrupaciones políticas de izquierda en los '50s. Ellas se sentían iguales a sus compañeros y no percibían situaciones de discriminación. Por eso, la mayoría pensó que la afamada obra de Simone de Beauvoir, El segundo sexo publicado en Francia en 1949 y en Buenos Aires en 1954 - atendía a los problemas de otras mujeres y no a los suyos. Fue más tarde, a fines de los '60s, cuando comprendieron que eso que les sucedía a "las otras" también las involucraba a ellas. María Elena Oddone, fundadora del Movimiento de Liberación Femenina (MLF), confirmó más tarde este efecto de lectura: "Me sentí deslumbrada. Vi escrita mi vida de mujer casada y madre de familia. En un lenguaje claro, directo, estremecedor, se contaba allí mi propia historia" (Odonne, 2001:65). ${ }^{1}$

También las obras de Sulamith Firestone, Kate Millet, Betty Friedan, Margaret Mead y las recopilaciones de las notas de las feministas radicales eran leídas y debatidas por las militantes

${ }^{1}$ La recepción de este libro fue heterogénea. En los países anglosajones, en donde la tradición individualista estaba más extendida, generó entusiasmo. De hecho, gran parte de su escritura De Beauvoir la había realizado entre sus viajes a Estados Unidos, alimentada por sus observaciones sobre las mujeres estadounidenses y el problema del racismo (Tinat, 2011). La sociedad francesa, en cambio, fue menos receptiva a los cuestionamientos de la diferencia sexual y el maternalismo (Offen, 1994). Puntualmente, las feministas del Movimiento de Liberación de las Mujeres rechazaron la primacía asignada a una idea individualista de la emancipación (Picq, 1993). 
argentinas (Calvera, 1990). Gabriela Christeller, María Luisa Bemberg - ambas fundadoras de la UFA -, Marisa Navarro y otras tantas, viajaban frecuentemente y acarreaban libros, algunos de los cuales traducían de manera casera, reformulaban conceptos, procuraban explicaciones y palabras de autoridad, aplicando una política de la traducción que no se dejaba limitar por las condiciones materiales de asimetría (Ciriza, 2013). ${ }^{2}$

Un buen ejemplo de estas reapropiaciones fue lo que sucedió con los grupos de concientización (en inglés consciousness-raising groups). Estos surgieron entre las feministas de Nueva York y Chicago, quienes recuperaron una vieja tradición de la izquierda que visualizaba el potencial emancipador de la experiencia personal. Los grupos se formaban con no más de doce mujeres y se planteaba un tema de discusión, por ejemplo, dependencia económica, violencia doméstica, menstruación, hijos o aborto. Todas las participantes tenían el derecho a hablar, sin que ninguna tuviera el monopolio de la palabra, y se dejaba muy en claro que no se trataba de una acción terapéutica sino política (Sarachild, 1978). Las feministas argentinas tomaron esta estrategia y la adaptaron:

la traducción literal, 'elevación de conciencia', resultaba demasiado vaga. 'Concientizar', de neto corte izquierdista, implicaba un movimiento de afuera hacia adentro, de dictar lo que la otra debía encontrar en su propio interior. 'Concienciar', en cambio, se adecuaba perfectamente al método casi mayéutico que se proponía. Lograba describir ajustadamente el proceso de sacar de sí, de dar nacimiento a la propia identidad (Calvera, 1990:37). ${ }^{3}$

2 En esta línea, puede citarse el estudio de Kathy Davies acerca del armado, circulación y recepción de Our Bodies, Ourselves (1era edición 1970), una reflexión sobre el proyecto transnacional del feminismo en tanto conocimiento y política, sus estrategias de localización y las relaciones entre los Estados Unidos (centro) y otros países (periferia).

3 Las feministas francesas también marcaron sus diferencias con el modelo de los Estados Unidos: ellas juzgaban y criticaban lo que se decía en los grupos de 
Otro tema en común entre la agenda feminista argentina y la agenda de los Estados Unidos y Francia fue la crítica a la exaltación social y comercial de la maternidad. Un volante de la UFA mostraba a una mujer, con ruleros y delantal, que cocinaba y tendía la ropa, junto a una TV encendida que reproducía un aviso de cosmética femenina para ser "sexy". Sus tres hijos reclamaban su atención: el bebé lloraba en sus brazos, el niño estaba montado sobre su cabeza y la niña acababa de cortar el cable del teléfono, una metáfora de la falta de vinculación de esta mujer con el mundo exterior sintetizada en la frase: "Madre: esclava o reina, pero nunca una persona" (UFA, s/f). Otro folleto denunciaba que el día de la madre era "el bombón para hacernos aceptar 80 horas de trabajo semanal no remunerado" (UFA, 1973). El Movimiento de Liberación Femenina, por su parte, denunciaba la falta de protección social de la maternidad, con jornada de trabajo ilimitada, sin salario, sin sindicato, ni descanso dominical, y la negación de esta situación por parte del sistema, "con regalos por un día, mientras la utiliza todo el año" (MLF, 1970). Oddone profundizaba su malestar en su autobiografía:

No falta en la televisión alguna profesional que dice con orgullo mentiroso "yo pude criar a mis hijos y hacer carrera'. Lo que no dice es que esclavizó a su madre, la abuela, para que se ocupara de lo que ella no podía hacer, o que fue otra mujer, una empleada, la que se ocupó de sus hijos, que para hacerlo debió abandonar a los propios (Oddone, 2001:115).

Según ella, la maternidad había "frenado el progreso de la especie humana, manteniendo a la mitad de la población en la esclavitud y la ignorancia con consecuencias letales" (Oddone, 2001:116).

En los boicots que se organizaban contra los festejos del Día de la Madre participaron también militantes del Frente de

concientización mientras que las estadounidenses explícitamente lo desaconsejaban (Picq, 1993). 
Liberación Homosexual de la Argentina (FLH), que se había formado en los inicios de los 70s (Rapisardi y Modarelli, 2001; Perlonguer, 1997; Sebreli, 1997). El Decreto 659 dispuesto por el gobierno peronista en febrero de 1974, que prohibía las actividades de planificación en dependencias públicas y obstaculizaba la venta libre de anticonceptivos, generó otra ocasión para actuar juntos. Esta medida había sido pensada por el peronismo como un modo de frenar la caída de la tasa de natalidad y sus efectos sobre la soberanía territorial y la economía nacional, además de ser un reaseguro moral ante las transformaciones en el orden de género y socio-sexual en curso (Felitti, 2012). En el contexto de Guerra Fría y extensión de los proyectos de cambio social radical la resistencia a esta medida no fue sencilla. Como recuerda Hilda Rais (2005): "La izquierda nos acusaba de estar a favor del Plan Mc Namara y de querer esterilizar a todas las mujeres de América Latina, y la derecha de proabortista". ${ }^{4}$ Leonor Calvera, militante de UFA, lo confirma: "la derecha nos acusaba de extremistas y contestatarias, y la izquierda de elitistas y burguesas" (Calvera, 1990:47). Por eso el texto que se repartió en la calle tuvo que ser muy claro: "No al embarazo no deseado" ( $\mathrm{N}^{\circ}$ del decreto ley en cuestión), No a la esterilización forzosa (Plan McNamara) - Por una maternidad consciente. MLF UFA" (Cano, 1982:87). ${ }^{5}$

${ }^{4}$ Robert McNamara ocupó el cargo de secretario de defensa del gobierno de los Estados Unidos entre 1961 y 1968. También fue presidente del Banco Mundial (1968-1981) e impulsó la creación del Fondo de las Naciones Unidas para la Población en 1969. Su nombre está fuertemente asociado a las presiones, directas e indirectas, que ejerció EE.UU en América Latina para bajar sus índices de natalidad.

${ }^{5}$ En los Estados Unidos la activista afroamericana Angela Davis (2005) también había denunciado el carácter racista y clasista de los enunciados en favor de la "maternidad voluntaria" del feminismo de fines del siglo XIX y del movimiento de control de la natalidad del siglo XX. Sin embargo, aunque gran parte del movimiento político, liderado por varones, consideraban que las familias numerosas podían ser un reaseguro contra la exterminación racial, algunas mujeres pensaban que embarazarse por ello era un costo demasiado alto, que terminaban asumiendo en soledad (Tone, 2001). Algo similar sucedió en Puerto 
En medio de la situación política que se vivía en la Argentina resultaba difícil conciliar la lucha por la liberación de la mujer y de la humanidad toda. Luchar por el control del propio cuerpo y la autonomía personal parecía a veces contradecir los ideales comunitarios de las agrupaciones de izquierda. Reivindicar el placer sexual y prepararse para la lucha armada sonaba incompatible. En Las mujeres dicen basta, uno de los pocos libros feministas que se publicaron durante esta segunda ola en la Argentina, Isabel Larguía, Peggy Morton y Mirta Henault (1970) advertían sobre los peligros de concentrar la lucha en el acceso al aborto y la anticoncepción, dado que esto por sí solo no aseguraba un cambio estructural. Según Larguía, la mujer "preocupada exclusivamente por establecer su dominio revanchista en el interior de la relación amorosa, postergará su integración a las luchas que tienden a destruir el sistema que la aprisiona" (1970:105). La moral privada que fomentaban estas "actitudes revanchistas" se oponía a la moral proletaria que, gracias a su rigidez permitiría avanzar en el camino de la revolución social. La consigna "mi cuerpo es mío" o el pensar a los hijos como propiedad privada eran ideas fuertemente debatidas en las agrupaciones de izquierda que pregonaban la solidaridad y la vida en comunidad. En varias agrupaciones las decisiones sobre los hijos (tenerlos o no tenerlos, cómo criarlos) se discutían colectivamente; la vida cotidiana estaba atravesada por la militancia (Oberti, 2015; Felitti, 2010b).

De ahí que fuera aún improbable plantear demandas utilizando un lenguaje de derechos humanos, de tradición liberal e individualista. De hecho la doble militancia, en el feminismo y en organizaciones de izquierda, era vivida con tensión. Por un lado porque incrementaba el alcance de la represión al duplicar los espacios y por otro, porque generaba fuertes discusiones sobre las

Rico, en donde algunas feministas denunciaron las pruebas médicas de la píldora anticonceptiva como una forma de dominación colonial, lo mismo que las campañas de esterilización, mientras que otras mujeres agradecían la oportunidad de acceder a cualquiera de estas alternativa con tal de no seguir teniendo hijos (Briggs, 2002). 
posiciones que debían asumirse ante hechos políticos clave, como sucedió ante la masacre de los presos políticos en la cárcel de Trelew (1972), ubicada al sur de la Argentina, o ante el golpe de Estado en Chile en 1973. ¿Era pertinente que una agrupación feminista se refiriera a estas cuestiones? ¿Podía separarse la situación de la mujer de su contexto?, fueron algunas de las preguntas que se hicieron entonces (Torres, 2005). A estas situaciones de tensión se sumaron otras: las disputas sobre las formas de organización - aceptar los liderazgos personales o defender a rajatabla la horizontalidad; el silencio de las lesbianas quienes por temor, vergüenza o estrategia no hablaban públicamente de su sexualidad, poniendo así en suspenso el sinceramiento propuesto por las técnicas de concienciación (Rais, 2005; Sardá y Hernando, 2001:65,121,137) y el cambio en la organización política que supuso golpe militar del 24 de marzo de 1976.

De forma paradojal, al mismo tiempo que la dictadura censuró y reprimió sus acciones, dio lugar a nuevos escenarios y contenidos, generados por los exilios y la fuerza que fue ganando el discurso de derechos humanos para denunciar al terrorismo de estado y la violación que hacían de ellos.

\section{Mirar y mirarse desde afuera}

El exilio argentino tuvo como protagonistas a militantes políticos y sindicales peronistas y de las distintas izquierdas adherentes a la lucha armada o no -, profesionales, intelectuales y personas sin una militancia significativa. A partir de los $60 \mathrm{~s} y$ especialmente entre 1976 y 1980, estas personas se refugiaron principalmente en México y España, y en menor medida en Suecia, Francia, Venezuela, Brasil, Bélgica, Holanda y Estados Unidos (Franco, 2008). ${ }^{6}$ Durante estos exilios, muchas mujeres tomaron conciencia de las situaciones de discriminación $e$

6 Sobre el exilio argentino pueden consultarse también: Yankelevich y Jensen, 2010; Yankelevich, 2009; Franco, 2008; Jensen, 1998. 
inequidad vividas durante su militancia, al disponer de más tiempo para la reflexión y comparar lo vivido con lo que sucedía en las sociedades de acogida. Así, aunque muchas peronistas y militantes de agrupaciones de izquierda cuando vivían en la Argentina no habían simpatizado ni apoyado al feminismo -al que consideraban un movimiento de elite, burgués, que distraía a las mujeres de su verdadera lucha- fueron varias las que regresaron al país reconociéndose como feministas (Barrancos, 2007:272). Algo así sucedió con militantes exiliados que se "descubrieron" latinoamericanos estando en el exterior (Franco, 2008).

Las exiliadas que llegaron a México se encontraron con una militancia femenina activa, que miraba de cerca la experiencia estadounidense y la suya propia, con los antecedentes de la movilización política del ' 68 y lo que había generado ser la sede de la Primera Conferencia Internacional sobre la Mujer organizada por las Naciones Unidas en 1975 (Fuentes, 2014; Acevedo, 2012; Bartra, Fernández Poncela y Lau, 2002). A su vez, a diferencia de lo que sucedía en la Argentina, el estado mexicano se interesaba por la planificación familiar y la presentaba como un derecho, como parte de una nueva política demográfica que atendía los altos niveles de fecundidad promedio ( 7 hijos por mujer) en un contexto de desempleo, inflación y aumento de la deuda externa (Cosio Zabala, 1994; Felitti, 2012b). Esta política volvió necesaria la revisión del "machismo" y su expresión en una paternidad numerosa y el fortalecimiento de las mujeres como tomadoras de decisiones.

La escritora argentina Tununa Mercado participó del movimiento feminista mexicano durante su exilio, colaborando con la revista Fem. Esta publicación ha sido considerada la primera revista feminista latinoamericana y es reconocida por la calidad de sus artículos, el reconocido nivel de sus colaboradoras y la preocupación que mostraban por enlazar las realidades de las mujeres mexicanas con las múltiples experiencias que atravesaban sus congéneres de América Latina (Grammático, 2011). Mercado recordó así su experiencia en Fem: "Fue un grupo solidario, un grupo atento a las luchas de América Latina. Fue un grupo muy politizado que nunca separó el feminismo de un concepto 
socialista y revolucionario" (Mercado, 2007). Teresita de Barbieri, académica feminista uruguaya exiliada en México desde 1974, también integró Fem desde sus inicios. Ella también valoró la apuesta editorial por la circulación de ideas, denuncias y estrategias de acción feministas. Se daba entonces una militancia en favor de los derechos de las mujeres y también por las luchas sociales y políticas que tenían lugar en la región. Se trataba de mostrar solidaridad y de sostener que el cambio en la situación de las mujeres no podría darse escindido de una transformación general. En el contexto de los primeros encuentros feministas, a partir de la década de 1980, ella recuerda la importancia que tomaron Fem y otras publicaciones: "Era usual ir con una maleta llena de revistas" (De Barbieri, 2010).

Aproximadamente 3.000 personas vivieron su exilio en Francia, la mayoría en París y sus alrededores (Franco, 2008). Allí las revueltas estudiantiles y obreras del 68 habían puesto en escena propuestas revolucionarias y contraculturales, con dimensiones políticas, económicas y también sexuales. Recordemos que una de las causas visibles del Mayo Francés había sido la prohibición de la entrada de los varones a los dormitorios de las chicas. El movimiento feminista francés tuvo su año paradigmático en 1970, con distintos acontecimientos como la reunión en la Universidad de Vincennes, la ofrenda a la mujer desconocida del soldado, la manifestación en la cárcel La Petite Roquette para denunciar la prisión de todas las mujeres y la interrupción de la conferencia de prensa en la que se presentaba un número especial de la revista Elle sobre la cuestión de la mujer en Francia, al que consideraron muy conservador (Riot Sarcey, 2008).

La caída de la natalidad a principios del siglo XX había generado una legislación que, desde la década de los 20s, prohibía la anticoncepción y el aborto, y que durante su momento de mayor rigidez bajo el régimen de Vichy (1940-1944), condenó a la guillotina a una mujer por practicarlos (Cova, 1996; Offen, 1996). Recién a fines de 1967 se volvió a autorizar la anticoncepción, pero existían muchas trabas en la práctica y la propaganda 
anticonceptiva seguía prohibida. De ahí que la lucha por la libertad reproductiva resultó tan importante y también tan resistida. El 5 de abril de 1971 Le Nouvel Observateur publicó un Manifiesto de 343 mujeres que declaraban haber abortado. La iniciativa provino de la revista y estuvo diseñada por periodistas comprometidas con el tema y por el Movimiento de Liberación de las Mujeres (MLF). Esta acción por la legalización del aborto le dio al feminismo francés una consigna aglutinadora y puso en evidencia un cambio de estrategia, al colocar el aborto libre y gratuito como un símbolo de emancipación, de liberación de las mujeres, y no sólo como un problema de salud pública (Pavard, 2012). En 1975, con el apoyo clave de Simone Veil al frente del Ministerio de Sanidad, el aborto pasó a ser legal aunque muchos problemas continuaron: no estaba cubierto por el seguro social, los objetores de conciencia ponían obstáculos a su práctica en los hospitales, la norma se refería más a la responsabilidad de la madre que a su libertad, no incluía a las menores ni a las extranjeras, solo era posible hasta la décima semana de gestación y se requería entrevista psicológica previa. De ahí que las militantes continuaran luchando por la ampliación y materialización de este derecho (Le Temps des femmes, 1, 1978:12).

Las latinoamericanas que llegaron a París encontraron este escenario de movilización política, de presencia feminista en la calle y en los medios, y sectores de izquierda que las apoyaban. Marina Franco (2010) realizó más de 60 entrevistas a emigrados políticos argentinos exiliados en Francia y si bien en sus preguntas las cuestiones de género no fueron centrales, el tema salió sin que se lo propusiera. En los relatos surgían referencias a las dimensiones íntimas, corporales, cotidianas que atravesaban el exilio. Para dar cumplimento con el mandato social que las ubicaba en el rol de cuidadoras y reproductoras de la vida familiar, muchas se vieron obligadas a asumir roles muy activos y así descubrieron su potencial. Por ejemplo, aprendían francés más rápido que sus compañeros porque lo hacían en situaciones cotidianas, como cuando iban a comprar al mercado. Para asegurar la subsistencia se insertaban en el mercado de trabajo, 
aunque el puesto no tuviera en cuenta sus calificaciones. Estas actitudes mostraban su fortaleza y al mismo tiempo, confirmaban su soledad. Franco relata la decepción que sintió una exiliada cuando tuvo que parir a su hijo sin su compañero. Existían justificaciones para esta ausencia ya que la pareja estaba haciendo trámites necesarios e impostergables. Además, en la Argentina la presencia de los varones en la sala de partos era una escena culturalmente extraña y por eso poco exigida. Sin embargo, al estar en Francia y saber que allí sí era frecuente que el padre presenciara el parto y acompañara a la mujer, el sentimiento de frustración se hizo inevitable (Franco, 2010).

Situaciones como estas impulsaron reflexiones y dieron lugar a diversos modos de circulación e intercambio entre las mujeres exiliadas allí y las que habían quedado en América Latina. El Grupo Latinoamericano de Mujeres en París surgió en 1973 como parte de estos procesos, cuando sus fundadoras se preguntaron qué tenían en común las francesas, mexicanas, argentinas, brasileñas, venezolanas, y qué significaba ser feminista en cada contexto. En busca de respuestas se reunieron en casas y en bares, formaron grupos de concientización y crearon su propio boletín de noticias, Nosotras, un nombre que evocaba la singularidad y la solidaridad femenina. Entre 1974 y 1976 publicaron 26 números, escritos en portugués y en español, dactilografiados y reproducidos en esténcil (Pedro, 2007). El boletín fue atravesando cambios editoriales y enfrentó dificultades de financiamiento, situación frecuente en las publicaciones feministas que, en este caso, se reforzaba porque sus editoras eran exiliadas y militantes de izquierda. Un problema puntual fue que la comunidad de exiliados de Brasil quería que el periódico se ocupara de denunciar a la dictadura, mientras que las mujeres del grupo se negaban a que su militancia feminista fuera instrumentalizada para otras luchas. Esto hizo que algunas tuvieran que dejar la agrupación ante presiones y amenazas, como 
la de retirarle el apoyo económico a las familias de las mujeres que participaran de la revista (Pedro, 2007). ${ }^{7}$

Uno de los objetivos de Nosotras fue sostener la idea del feminismo como movimiento internacional y poner en contacto a las militantes francesas con las latinoamericanas y a éstas entre sí. Bajo el título "Dos experiencias del grupo" en una nota comentaron dos propuestas para alcanzar este fin y sus resultados. La primera propuesta había sido publicar una entrevista a Simone de Beauvoir para "hacer descubrir a la mujer latinoamericana algunas mujeres europeas y su trabajo en relación con diferentes corrientes del movimiento feminista internacional" pero finalmente no pudo hacerse. La periodista, también latinoamericana, pensaba que era mejor dirigir el texto a las mujeres de la elite intelectual para que fueran ellas quienes transmitieran el mensaje a las masas, y las redactoras de Nosotras buscaban un discurso accesible para las mujeres de todos los sectores sociales, sin necesidad de mediaciones. La otra acción fue la proyección del reportaje de Jane Fonda y Delphine Seyrig sobre la mujer en Vietnam en presencia de una mayoría de feministas francesas $e$ italianas. Tampoco esta experiencia resultó exitosa: para las europeas el documental era viejo y reformista, mientras que para las latinoamericanas seguía siendo valioso (Nosotras, 4, 1974).

Estos dos ejemplos muestran algunas de las diferencias que atravesaban al feminismo en su amplitud y por ende, la necesidad de armar un movimiento propio, latinoamericano: "producto de nuestra realidad, que obedezca a nuestro contexto socio cultural y económico. No podemos caer en la importación de esquemas, estrategias con respecto a la liberación de la mujer (...) en

7 El Círculo de Mujeres de Brasil fue otro grupo importante para las exiliadas. En 1975 publicaron el primer número de Agora é que são elas (Goldberg-Salinas, 2000; Gonçalves de Abreu, 2006). Si bien organizaron acciones de concientización, adscribían más fuertemente a la lucha de clases y tuvieron menos resistencias para denunciar la violación de derechos humanos en Brasil. Aún con sus diferencias, tanto el Círculo como Nosotras, desde sus propias denominaciones, remitían al ciclo, a la hermandad entre las mujeres (Pedro y Scheibe Wolff, 2007). 
resumen, nuestra diferencia es que la latinoamericana tiene un enemigo común metido en su vida cotidiana: el imperialismo y así están más expuestas a la represión, la europea se vería amenazada solo en caso de guerra. Esto hace que si el objetivo es el mismo: la liberación de la mujer - la táctica y la forma de sentir son bien diferentes" (Nosotras, 4, 1974:9).

Este compromiso se manifestaba en el espacio dedicado a la difusión de noticias sobre la situación de la mujer en diferentes países (Venezuela, México, Brasil, Colombia, Ecuador), así como en los comentarios sobre la Conferencia de la Mujer en México en 1975, ocasión que las redactoras consideraban oportuna para avanzar en la creación de un movimiento feminista latinoamericano. Las noticias publicadas sobre la Argentina se refirieron a las dos organizaciones presentadas en el apartado anterior. Por un lado se comentó la recepción de la revista Persona del Movimiento de Liberación Femenina (MLF), señalando que su editorial coincidía con los objetivos de Nosotras: "aportes de lugares distantes o cercanos en el tiempo y espacio son igualmente válidos para obrar como espejo donde cada una de nosotras pueda mirarse" (Nosotras, 13/14, 1975:1-2). En el número siguiente se presentó a la Unión Feminista Argentina (UFA), sus principios, la explicación que daban al sexismo y su premisa: la liberación de la mujer se dará por obra de las mujeres mismas (Nosotras, 15, 1975:5-6). Es importante señalar que, más allá de este reconocimiento de las especificidades del ser mujer latinoamericana, las editoras no quisieron dar a entender que el machismo o la discriminación laboral fueran solamente un problema de América Latina (Nosotras, 7, 1974:4-6,13). Más bien, los veían como problemas mundiales ligados a la explotación de clase. $^{8}$

La sección dedicada a la correspondencia era otro ámbito de intercambio; allí se publicaron cartas procedentes de diferentes lugares del mundo y entre ellos, la Argentina. En una de estas

8 Una nota sobre la explotación que surge del trabajo domestico se publica en Paris y también en Brasil, mostrando lo multilocal del problema (Pedro, 2007). 
cartas, Sara (Torres) de la UFA contó que hacía circular Nosotras entre su grupo. Por su parte, María Elena (Oddone) del MLF se alegraba de poder enterarse "cómo están las cosas en París" (Nosotras, 6, 1974:11). En otra carta una militante de la UFA celebraba la creación del Tribunal Internacional de Crímenes cometidos contra las Mujeres (que sesionó en Bruselas en 1976) y se comprometía a enviar información sobre casos de la Argentina (Nosotras, 14/15, 1975), algo que también promete Oddone en otra comunicación. Por su parte, Hadalli Gleizer de la UFA celebraba saber que hay brasileras feministas porque: "A veces nos sentimos un poco solas..." (Nosotras, 8/9/10, 1974:19). Para el último número del boletín la sección de correspondencia había pasado de una página a tres.

En esta época, el feminismo francés lanzó revistas que también difundían noticias de los movimientos de otros países y algunas denuncias sobre la violación de los derechos humanos en el Conosur. Una de ellas fue Le Torchon Brûle, obra del Movimiento de Liberación de las Mujeres (Mouvement de libération des femmes - MLF), cuyo número 0 apareció encartado en l'Idiot Liberté en diciembre de 1970. Entre mayo de 1971 y el verano de 1974 se publicaron seis números de aparición "menstruel" (menstrual), con encargadas rotativas para así evitar el control jerárquico que podría asumir un comité de redacción. En ellos encontramos artículos teóricos, testimonios, debates, poesía, ficción e información, con un diseño vivaz, de muchos colores, que incluía fotomontajes e historietas. La crítica al deber de maternidad fue tema de un dossier en el cual pueden leerse consignas muy similares a las que circulaban en las organizaciones de la Argentina, por ejemplo: "Travail, Famille, Patrie, y 'en a marre. Fêtées une journée, exploitées toute l'année" ("Trabajo, Familia, Patria, nos tienen hartas. Festejadas un día, explotadas todo el año") (Le Torchon Brûle, 1971). Quedaba así en claro que la maternidad y el trabajo doméstico eran imposiciones sociales que atravesaban a las mujeres de un lado y del otro lado del Atlántico.

En el número 5 se publicó un anuncio de las reuniones del Grupo de Mujeres Latinoamericanas y una nota sobre el golpe de 
estado en Chile. Esto último había sido una decisión discutida. Como pasó en la UFA, las integrantes se preguntaban si esto era algo importante para la revista o si sólo debían ocuparse de las luchas específicas de las mujeres. Finalmente, fue la fuerza del llamado "grupo de los jueves", de orientación política radical, la que logró que se hiciera espacio para la política exterior en el último número (Picq, 1993).

Le Temps des femmes apareció en 1978 y reunió a varios grupos de mujeres, generalmente sindicalizadas, que entendían la liberación femenina como parte de la lucha por el socialismo. En sus páginas hallamos denuncias a las esterilizaciones forzosas que se realizan en América Latina y hay noticias puntuales sobre la Argentina. En su número inaugural una nota habla de las torturas y violaciones de las que son objeto las presas políticas en éste país (Le Temps des femmes, 1, 1978:4), mientras que otra convoca a realizar un boicot al mundial de fútbol de 1978 con sede en la Argentina. Además, hay una invitación para sumarse a una delegación de mujeres, entre ellas Simone de Beauvoir, que junto con familiares de muertos y desaparecidos iban a presentar en la Embajada argentina un pedido de habeas corpus por la desaparición de cuatro mujeres (Le Temps des femmes, 1, 1978:12).

En este primer número, se publicó una entrevista de dos páginas a una "feminista argentina". Delia, de 45 años, militante de la UFA, explicaba allí detalles del funcionamiento de la organización. Destacaba su defensa de la horizontalidad, las acciones realizadas contra los festejos del Día de la madre, mencionaba el libro Las mujeres dicen basta - antes citado -, los intentos por contactar a militantes presas políticas y su fracasos, $y$ explicaba la ruptura de 1973 a partir de la discusión que generó la posición que debía tomarse acerca de la masacre de Trelew. Fue en ese momento que Delia dejó la UFA y se unió al Grupo de Mujeres Trabajadoras, creado ese mismo año con otras compañeras de sindicatos (Le Temps des femmes, 1, 1978:44-45). Es interesante observar que esta reseña de la organización y sus dinámicas fue objeto de estudio reciente de la historiografía 
feminista pero era ya accesible para las feministas francesas lectoras de esta revista a fines de los 70s.

En el segundo número, Le Temps des femmes denunció nuevamente la situación de las presas políticas en Argentina y transcribió una carta que detallaba las torturas y los fusilamientos, junto con los testimonios de tres mujeres que había estado detenidas en la cárcel de Villa Devoto, ubicada en la Cuidad de Buenos Aires. En esa nota ellas cuentan sus vivencias e informan sobre los espacios que existen para expresar solidaridad, como Amnesty y CIMADE (Comité Inter-Mouvements Auprés Des Evacues) sección América Latina (Le Temps des femmes, 2, 1978:4042). En el número tres los pedidos de apoyo para Argentina y Chile se reiteran (Le Temps des femmes, 3, 1978) y luego no se encuentran más menciones específicas. Estas notas mostraban la línea editorial de la revista y también los resultados de las acciones (campañas de solidaridad y denuncias) que organizaban los emigrados políticos en Francia en el contexto del mundial de fútbol de 1978 (Franco, 2008).

Otra publicación que acusa la violencia de las dictaduras en el Conosur es Choisir, la cause des femmes, homónima del movimiento creado en julio de 1971 por Gisèle Halimi, Simone de Beauvoir (primera presidenta de la asociación), Jean Rostand y Christiane Rochefort, entre otras. ${ }^{9}$ En sus distintos números podemos leer la denuncia de una militante chilena, exiliada en París desde 1975, que había sido torturada en la cárcel (Choisir, 39, 1979:19), el aviso de la desaparición de Adriana Amalia Lesgart, una de las fundadoras de la Agrupación Evita, rama femenina de Montoneros (Choisir, 44, 1979:25) y explicaciones sobre la lucha de

\footnotetext{
9 La agrupación tomó notoriedad en 1972 con el "Proceso de Bobigny". Halimi, que era abogada, asumió la defensa de una joven de 16 años que había interrumpido su embarazo, resultado de una violación, con la ayuda de su madre. Ambas mujeres y otras tres más fueron llevadas a un juicio en donde se puso claramente en evidencia las relaciones entre clase social y aborto. La joven sufría el peso de la ley restrictiva de 1920 mientras que quienes tenían recursos económicos viajaban a Inglaterra para abortar legalmente (Choisir, la cause des femmes, sitio web).
} 
las Madres de Plaza de Mayo, a quienes el informe presenta como "locas bien razonables", retomando de manera crítica el adjetivo de "locas" que les asignaba el gobierno militar argentino (Choisir, $45,1980,13)$. Esta nota se redactó para dar cuenta del encuentro de 4 madres de la Plaza de Mayo con el presidente francés Valéry Giscard d'Estaing. Allí se mencionaban las marchas silenciosas de los jueves al mediodía frente a la Embajada argentina en París y se hablaba ya de los "vuelos de la muerte", es decir, de los lanzamientos de los detenidos desaparecidos desde aviones militares que sobrevolaban el Río de la Plata, hecho aberrante que en Argentina se haría público bastante después.

En marzo de 1980, cuando se produjo un nuevo aniversario del golpe militar y el gobierno de facto anunció una disposición que establecía que una persona desaparecida por más de tres meses debía considerarse muerta, la revista publicó una entrevista a dos exiliadas. Una tenía 48 años, tres hijos desaparecidos y había llegado a Francia en 1977; la otra tenía 25, y hacía 7 meses que era refugiada, luego de tres años y medio de estar en la cárcel en la Argentina. En el relato de ambas aparecían sus opiniones sobre el escenario político en general y la situación particular que vivían las mujeres. Las dos ponían en valor el discurso de los derechos humanos aunque dudaban que pudieran lograrse esos derechos para las mujeres si no se daba una transformación social general. La militante de más edad no definía a la dictadura argentina como una "violación de los derechos del hombre" pero cuando le preguntaron si las mujeres francesas eran más libres que las argentinas, su posición fue más dubitativa:

Es difícil de decir. En Argentina no hay divorcio pero a partir de que una mujer vive con un hombre tiene los mismos beneficios como si estuviera casada. El aborto prohibido. Salarios en equidad. Acceso a todas las carreras. Leyes progresistas que nunca se aplican.

Para ella no había un movimiento feminista en Argentina; recién al llegar a Francia entendió de qué se trataba "eso". La más joven 
mantenía la posición más frecuente entre las militantes: "el feminismo está bien para los países desarrollados. Allá la lucha es común. No hay sexo privilegiado en las torturas. Es el ser humano que piensa diferente" (Choisir, 46, 1980:7-10). Como puede verse en estos testimonios, las tensiones de la doble militancia y las dificultades para pensar los términos de la emancipación atravesaban las fronteras.

En esta época, no sólo las feministas mujeres tejían sus redes, también el movimiento homosexual tendía las suyas. El Frente Homosexual de Acción Revolucionaria (Front homosexuel d'action révolutionnaire) comenzó a manifestarse en 1971, con un discurso que insistía en la alegría y rechazaba el victimismo, valiéndose de consignas como "Abajo la dictadura de los normales". Tal como hacía el Frente de Liberación Homosexual de la Argentina, sus integrantes participaron junto a las feministas en los boicots a las fiestas de las madres y editaron Masques, revue des homosexualités, una revista de muchas páginas, con una edición muy cuidada, artículos que citan bibliografía, críticas de libros, de ópera, de cine y de teatro, y entrevistas a personas reconocidas en el mundo público. En 1981 la revista publicó un dossier dedicado al exilio y la represión en la Argentina. En él se denunciaban las muertes y las desapariciones, la complicidad del Episcopado católico y del Partido Comunista, y se destacaba la lucha de las Madres de Plaza de Mayo (Masques, 11, 1981:18-38), pero el tema central era la situación de los homosexuales bajo la dictadura militar. En las veinte páginas del suplemento podían leerse las entrevistas a los escritores exiliados Manuel Puig y Copi, junto con el informe del periodista europeo Antón Leicht sobre su encuesta e investigación en Argentina. Leicht comenzaba su escrito contando las humillaciones que padeció al pisar suelo argentino por el solo hecho de ser "puto", para luego avanzar en su descripción y análisis de diferentes momentos de la historia argentina en relación a la homosexualidad. Aquí se explicaban algunos hitos de la persecución gay: los edictos policiales del peronismo, las razzias policiales del gobierno del general Juan Carlos Ongania (1966-1970), las acciones de la Triple A (Alianza 
Anticomunista Argentina) en acción durante el tercer gobierno peronista (1973-1976) y lo que sucedía bajo la última dictadura militar, a partir del relato de varios entrevistados, la mayoría militantes del FLH. Nuevamente, como antes remarqué en relación a la circulación de la historia de UFA en una revista feminista parisina en los '70s, es también llamativo encontrar este artículo, con información detallada y relatos de primera mano sobre la especificidad de la represión homosexual. Como sucedió con la historia del feminismo de la "segunda ola" en la Argentina, la recuperación de esta historia por parte de la academia y el activismo ha sido mucho más reciente.

\section{Conclusiones}

En el pensamiento y en la práctica feminista contemporánea se valoran la circulación, el intercambio y la solidaridad entre movimientos, entre mujeres, entre géneros, entre seres humanos. Pensar las identidades en su diversidad, en sus intersecciones, es presentado como ineludible. En el caso del feminismo del Tercer Mundo se insta a tener una voz propia, a desarrollar un pensamiento crítico de acuerdo a la historia colectiva, sin incorporar consignas del "Norte global" que no respondan a realidades y necesidades específicas del "Sur global". En los años 70 s estas premisas ya se habían hecho carne en muchas mujeres. Las que estaban en Argentina sentían el malestar de su condición de género aunque no pudieran aún expresarlo de ese modo. Ellas buscaban respuestas, investigaban, se abrían a nuevos marcos de interpretación al tomar conceptos y estrategias de las feministas estadounidenses y de las europeas, sin dejar de ponerles su propia impronta.

De este modo, las traducciones no se limitaban a cambiar la lengua de las palabras, la localización de muchas de estas ideas en contextos de revolución social y política, efervescencia cultural y represión estatal planteaba otros desafíos. El libre acceso a la anticoncepción y al aborto en tanto derecho individual, personal, entraba en colisión, por un lado, con los objetivos poblacionistas 
estatales de la Argentina y los dictados morales de la Iglesia católica, y por el otro, con el pensamiento de la izquierda, que planteaba a los hijos como una fuerza revolucionaria de recambio y al feminismo como una distracción burguesa.

El exilio político que generaron las dictaduras puso en movimiento a miles de personas. En estos procesos muchas mujeres latinoamericanas que huían del Conosur, revisaron sus propias experiencias y creencias sobre la militancia, el ser mujer y la sexualidad femenina en la distancia de otras geografías y con los aportes de los feminismos que allí encontraban. Hubo coincidencias: el boicot a las fiestas de las madres se repetía en distintas latitudes porque así de extendida era la obligación de maternidad impuesta a las mujeres. Lo mismo que las luchas por la legalización del aborto, derecho que en los Estados Unidos y en Francia se reconoció en los '70s y en América Latina sólo en la Ciudad de México en 2007. Así como muchos exiliados se descubrieron latinoamericanos cuando dejaron sus países de origen, fueron varias las mujeres que se volvieron feministas y comprendieron lo que implicaba el género. De hecho, las denuncias sobre la represión comenzaban a tener en cuenta esta dimensión, como cuando se prestó atención especial a la vida cotidiana de los homosexuales bajo la dictadura o a la situación de las presas políticas, sin dejar de subrayar el hecho de que la tortura era hacia el ser humano, más allá de su sexo.

Justamente fue esa noción de derechos humanos la que comenzó a adquirir un valor, en tanto fórmula que permitía hacer inteligible en el exterior los crímenes de la dictadura militar. Este lenguaje dio también la oportunidad de enunciar el derecho a decidir sobre el propio cuerpo, en un momento de la historia argentina en el cual los cuerpos no estaban, los cuerpos desaparecían. Ese discurso de derechos hoy tan aceptado, valorado, respetado y defendido no revestía el mismo reconocimiento en aquel momento. Para la izquierda se trataba de un discurso liberal, burgués, mientras que para la derecha su defensa significaba cuestionar sus propias acciones. Un momento clave para situar estos cambios fue la visita de la Comisión 
Interamericana de Derechos Humanos (CIDH) en 1979, un acontecimiento que permite observar el reacomodamiento político local e internacional con respecto al tema de los derechos humanos. Esta visita, que respondía entre otras cosas al trabajo de los exiliados y las exiliadas, representó un sorpresivo punto de quiebre. Los organismos de derechos humanos, los y las militantes populares apresados/as, y los y las sobrevivientes en el exilio, encontraron en el discurso de la OEA en torno a los derechos humanos la posibilidad de erosionar al régimen militar (D'Antonio, 2010).

Junto con esos grupos de solidaridad que se tejían entre los exiliados, las exiliadas armaron los propios, entre ellas y con las mujeres de los países que las acogieron. La presencia de una argentina y una uruguaya en la revista mexicana Fem, la formación de grupos de exiliadas latinoamericanas en el exterior, y la publicación de noticias del feminismo argentino y de los crímenes de la dictadura en revistas feministas francesas, fueron formas de seguir extendiendo la red, una circulación que había comenzado a fines en los sesentas con los viajes personales, con valijas llenas de libros, preguntas debates y estrategias.

Como ha desarrollado Joan Scott (2001), las mujeres no son meras portadoras o poseedoras de la experiencia sino que están constituidas por ella. Estas lecturas, viajes, exilios, escrituras, y acciones, muestran una preocupación del feminismo por tender redes y denunciar la violencia, mucho antes de que la revolución de Internet lo hiciera instantáneo. Este artículo se propuso visibilizar esa historia y aportar a uno de los desafíos constitutivos del discurso político feminista, las tensiones entre su contenido burgués y por lo tanto individualista, y su apuesta sororal. A su vez, historiza las posibilidades y limitaciones de un discurso de derechos humanos que hoy parece indiscutible y se muestra exitoso, aunque hasta hace poco haya sido visto por algunos grupos como una importante limitación para un cambio social radical. 


\section{Referencias bibliograficas}

ACEVEDO, M. La marcha que ha durado cuatro décadas. Entrevista por Mario Gutiérrez. In: GARCía PALAFOX, G. (ed.) 20 años. Por todas las mujeres. México D.F., Grupo de Información en Reproducción Elegida (GIRE), 2012, pp.42-45.

Aldaburu, M. I.; Cano, I.; Rais, H. y Reynoso, N. Diario Colectivo. Buenos Aires, La Campana, 1982.

Álvarez, S. Engendering Democracy in Brazil: The Women's Movements in Transition Politics. Princeton, Princeton University Press, 1990.

BARRANCOS, D. Mujeres en la sociedad argentina. Una historia de cinco siglos. Buenos Aires, Sudamericana, 2007.

Bartra, E.; Fernández Poncela, A., LAU, A. Feminismo en México Ayer y Hoy. Ciudad de México, Molinos de Viento, 2002.

BELUCCI, M. Las luchas de las mujeres por los derechos sexuales. In: ForASTElli, F. y TRIQUell, X. (comp.) Las marcas del género. Configuraciones de la diferencia en la cultura. Centro de Estudios Avanzados, Universidad de Córdoba, 1990, pp.105-116.

BiDASECA, K. Perturbando el texto colonial. Los estudios (pos)coloniales en América latina y sus mujeres. Buenos Aires, San Benito, 2010.

BIDASECA K. y VÁzQUEZ LABA, V. (comps.) Feminismos y Poscolonialidad. Descolonizando el feminismo desde y en América Latina. Buenos Aires, Godot, 2010.

BRIGGS, L. Reproducing Empire: Race, Sex, Science and U.S. Imperialism in Puerto Rico, California: University of California Press, American Crossroads Series, 2002.

Calvera, L. Mujeres y feminismo en la Argentina. Buenos Aires, Grupo Editor Latinoamericano, 1990.

CANO, I. El movimiento feminista argentino en la década del '70. Todo es Historia, n. 183, Buenos Aires,1982, pp.84-93.

CHEJTER, S. Feminismo por feministas. Fragmentos para una historia del feminismo argentino 1970-1996. Travesías. Temas de debate feminista contemporáneo, año 4, n. 5, Buenos Aires, 1996.

COSSE, I. Los nuevos prototipos femeninos en los años 60 y 70: de la mujer doméstica a la joven liberada. In: ANDÚJAR, A. et allí. De 
256 Traduciendo prácticas, tejiendo redes, cruzando fronteras

minifaldas, militancias y revoluciones, Buenos Aires, Luxemburg, 2009, pp.171-186.

Cosio-Zavala, M. E. Changements de fécondité au Mexique et politiques de population. Paris, L'Harmattan/IHEAL, 1994.

CostA, C. de L. As publicações feministas e a política transnacional da tradução: reflexões do campo. Estudos Feministas, vol. 11, n. 1, Florianópolis-SC, 2003, pp.254-264.

- Repensando el género: tráfico de teorías en las Américas. In: FEMENÍAS, M. L. (comp.) Perfiles del feminismo Iberoamericano. Vol.1. Buenos Aires, Catálogos, 2002.

CovA, A. El feminismo y la maternidad en Francia: teoría y práctica política, 1890-1918. In: Bock, G. y THANE, P. (eds.) Maternidad y políticas de género: la mujer en los estados de bienestar europeos, 1880-1950. Madrid, Cátedra, 1996, pp.215-244.

D'ANTONIO, D. C. Derechos humanos y estrategias de la oposición bajo la dictadura militar argentina. World Tensions / Tensões Mundiais, vol. 6, n.11, Observatorio das nacionalidades, Itaperi, Fortaleza, 2010, pp.153-178.

DAVIS, A. Mujer, raza y clase. Madrid, Akal, 2005.

DAVIS, K. The Making of Our Bodies Ourselves. How Feminism Travels across Borders, Duke University Press, 2007.

DE BARBIERI, T. Entrevista de la autora. Ciudad de México, 20 de mayo de 2010.

FelitTI, K. La revolución de la píldora. Sexualidad y política en la Argentina de los sesenta. Buenos Aires. Buenos Aires, Edhasa, 2012a.

. Planificación familiar en la Argentina de 1960 y 1970: ¿un caso original en América Latina? Estudios Demográficos y Urbanos n. 79, El Colegio de México, México DF, 2012b, pp.153-188.

. Sexualidad y reproducción en la agenda feminista de la segunda ola en la Argentina (1970-1986). Estudios Sociológicos, n.84, El Colegio de México, México DF, 2010a, pp.791-812.

- Poner el cuerpo: género y sexualidad en la política revolucionaria de Argentina en la década de 1970. In: BLOCH AVITAL H. (ed.) Political and social movements during the Sixties and Seventies in the Americas and Europe/ Movimientos politicos y 
sociales de los años sesenta en las Américas y Europa. Colima, Universidad de Colima, México, 2010b, pp.69-93.

FEMENIAS. M. L. Bibliografía sobre Feminismos y postcolonialidad. Andamios. Revista de Investigación Social, vol. 8, n. 17, 2011, Universidad Autónoma de la Ciudad de México, pp.133-141.

. Esbozo de un feminismo Latinoamericano. Estudos Feministas, vol.15, Florianópolis-SC, n.1, 2007, pp.11-25.

FRANCO, M. El exilio como espacio de transformaciones de género. In: ANDÚJAR, A.; D’ANTONIO, D.; GRAMMÁTICO, K. y ROSA, M. L. (comp.) Hilvanando historias: mujeres y política en el pasado reciente latinoamericano. Buenos Aires, Luxemburg, 2010, pp.127-145.

. El exilio: argentinos en Francia durante la dictadura. Buenos Aires, Siglo XXI, 2008.

FUENTES, P. Entre reivindicaciones sexuales y reclamos de justicia económica: divisiones políticas e ideológicas durante la Conferencia Mundial del Año Internacional de la Mujer. México, 1975. Secuencia. n. 89, mayo-agosto 2014, pp.163-192.

GIL LOZANO, M. F. Surgimiento de prácticas propias. Experiencias de la Segunda Ola en Argentina y Uruguay (1960-2000). In: MORANT, I. (dir.), Gómez-Ferrer, G.; Lavrin, A.; CANo, G. y Barrancos, D. (comps.) Historia de las mujeres en España y América. América Latina. Del siglo XX a los umbrales del siglo XXI, vol. IV, Madrid, Cátedra, 2006, pp.881-902.

GoldBerg-Salinas, Anette. Brésiliennes en exil. Cahiers du Cedref n. 8/9, París, 2000, pp.43-66.

GonÇAlves De Abreu, M. L. Feminismo no exílio: Círculo de Mulheres, Brasileiras em Paris. Disertación Tesis de Maestría- IFCH-Unicamp, Campinas, 2010.

GRAMMÁTICO, Karin. Feminismos en clave latinoamericana: un recorrido sobre Fem, Isis y Fempress. Mora, v.17, n. 2, Facultad de Filosofía y Letras, Universidad de Buenos Aires, 2011.

Henault, M.; MorTon, P.; LaRguía, I. Las mujeres dicen basta. Buenos Aires, Nueva Mujer, 1970.

JENSEN, S. Los exiliados: la lucha por los derechos humanos durante la dictadura militar, Buenos Aires, Sudamericana, 2010. 
258 Traduciendo prácticas, tejiendo redes, cruzando fronteras

MERCADO, T. Desgrabaciones del III Encuentro Internacional de Publicaciones Feministas. Buenos Aires, noviembre de 2007.

NARI, M. No se nace feminista, se llega a serlo. Lecturas y recuerdos de Simone de Beauvoir en Argentina, 1950 y 1990. In: ACHA, O. y HALPERIN, P. (comp.). Cuerpos, géneros, identidades. Estudios de historia de género en Argentina. Buenos Aires, Del Signo, 2000, pp.292-308.

. Abrir los ojos, abrir la cabeza: el feminismo en la Argentina de los años 70, Feminaria, año 9, núm. 18/19, 1996, pp.15-21.

OBerTI, A. Militancia, vida cotidiana y afectividad en los setenta. Buenos Aires, Edhasa, 2015.

OdDONE, M. E. La pasión por la libertad. Memorias de una feminista. Buenos Aires, Colihue - Mimbipá, 2001.

OFFEN, K. El cuerpo político: mujeres, trabajo y política de la maternidad en Francia, 1920-1950. In: BOCK GISELA y THANE Pat (eds.) Maternidad y políticas de género: la mujer en los estados de bienestar europeos, 1880-1950. Madrid, Cátedra, 1996, pp.245-278.

. Definir el feminismo. Un análisis histórico comparativo. Zona Franca, año II, n. 3, septiembre de 1994, pp.15-31.

OLIVEIRA RAmOS, T. R. (eds.) Leituras em rede: gênero e preconceito. Florianópolis, Mulheres, 2007, pp.307-328.

PAVARD, B. Si je veux, quand je veux. Contraception et avortement dans la société française (1956-1979). Rennes, PUR, 2012.

Pedro, J. M. Nosotras, Nós Mulheres, Nos/Otras, Noidonne. Rede de divulgação feminista dos anos 70 e 80. In: SCHEIBE WOLFF, C. (org.) Leituras em rede: gênero e preconceito. Florianópolis-SC, Ed. Mulheres, 2007, pp.307-328.

Pedro, J. M. y SCHEIBE WolfF, C. Nosotras e o Círculo de Mulheres Brasileiras: feminismo tropical em Paris. ArtCultura, v. 9, n. 14, 2007, pp.55-69.

Perlonguer, N. Historia del Frente de Liberación Homosexual de la Argentina. In: Prosa Plebeya. Ensayos 1980-1992. Buenos Aires, Colihue, 1997, pp.77-85. [1985]

PERÓN, E. La razón de mi vida. Buenos Aires, Peuser, 1951. 
PICQ, F. Libération des femmes: les années mouvement. Paris, Édition du Seuil, 1993.

RAIS, H. Entrevista de la autora. Buenos Aires, 16 de marzo 2005.

RAPISARDI, F. y MODARELlI, A. Fiestas, baños y exilios. Los gays porteños en la última dictadura. Buenos Aires, Sudamericana, 2001.

Riot SARCEy, M. Histoire du féminisme. La Découverte, Paris, 2008.

Rodriguez AgÜero, E. y CiRizA, A. Viajes apasionados. Feminismos en la Argentina de los 60 y 70. Labrys. Etudes Feministes/Estudos Feministes, n. 22, Universidad de Brasilia, Brasilia, 2012 [http://www.labrys.net.br/labrys22/sumarios/sumariogeral.htm].

SARACHILD, K. Consciousness-Raising: A Radical Weapon. In: AA.VV. Feminist Revolution. New York, Random House, 1978, pp.144-150.

SARDÁ, A. y HeRnANDO, S. No soy un bombero pero tampoco ando con puntillas. Lesbianas en Argentina: 1930-1976, Ontario, Bomberos y Puntillas, 2001.

ScoTT, J. Experiencia. La ventana (13), Universidad de Guadalajara, México, 2001, pp.42-73.

SeBRELI, J. J. Historia secreta de los homosexuales en Buenos Aires. In: SEBRELLI, J. J. Escritos sobre escritos, ciudades bajo ciudades, Buenos Aires, Sudamericana, 1997, pp.275-370.

SNYDER, C. R. What Is Third-Wave Feminism? A New Directions Essay. Signs, vol. 34, n. 1, University of Chicago Press, 2008, pp.175-196.

Soto, M. Cuando las mujeres dijeron UFA. Entrevista a Hilda Rais. Las 12, Página 12, 8 de enero de 2010.

TINAT, K. Introducción. In: TINAT K. (org.) La herencia Beauvoir. Reflexiones críticas y personales sobre su vida y obra. Ciudad de México, El Colegio de México, 2011, pp.11-32.

TONE, A. Devices and Desires. A History of Contraceptives in America. Nueva York, Hill and Wang, 2001.

TORRES, S. Entrevista de la autora. Buenos Aires, 26 de enero 2005.

TREBISACCE, C. Una segunda lectura sobre las feministas de los '70 en Argentina. Conflicto Social. Revista del Programa de Investigaciones sobre Conflicto Social, Instituto de Investigaciones Gino Germani, Facultad de Ciencias Sociales, UBA, año 3, n. 4, dic. 2010, pp.26-52. 
TreBISACCE, C.; TORELlI, M. L. Memorias feministas, ni escritas ni contadas, guardadas: metiendo las narices en el archivo personal de una feminista argentina de los años setenta. Kula. Antropólogos del Atlántico Sur. Revista de Antropología y Ciencias Sociales, n. 4, abr. 2011, pp.76-94.

VASALLO, A. Las mujeres dicen basta: feminismo, movilización y política en los setenta. In ANDÚJAR, A. et allí. Historia, género y política en los '70. Buenos Aires, Feminaria, 2005, pp 61-88.

VÁZQUEZ LABA, V. (Dir.) Voces desde los márgenes. Mujeres inmigrantes, violencia y ciudadanía en Mallorca-España. Universitat de les Illes Balears, 2012.

VeIGA, A. M. Circulación, redes y feminismo: una historia en tiempos de dictaduras, Argentina y Brasil. In: ANDÚJAR, A. et allí. De minifaldas, militancias y revoluciones, Buenos Aires, Luxemburg, 2009, pp.83-100.

YankeleVich, P. Ráfagas de un exilio. Argentinos en México, 1974-1983. México, El Colegio de México, 2009.

YANKElEVICH, P. y JeNSEN, S. Exilios: destinos y experiencias bajo la dictadura militar. Buenos Aires, El Zorzal, 2007.

\section{Documentos}

MLF. Volante Día de la Madre, Buenos Aires, 1970. Archivo personal de Sara Torres.

UFA. (s/f). Volante Día de la Madre. Buenos Aires, UFA, s/f. Archivo personal de Sara Torres.

Volante Día de la Madre, Buenos Aires, UFA, 1973. Archivo personal de Sara Torres.

\section{Revistas}

Choisir, la cause des femmes

Le Torchon Brûle

Le Temps des femmes

Nosotras

Masques, Revue des homosexualités 